\title{
Ginseng Production in Korea
}

\author{
John T.A. Proctor \\ Department of Horticultural Science, University of Guelph, Guelph, Ont. N1G 2W1, Canada
}

Jong Chul Lee

Suwon Experiment Station, Korean Ginseng and Tobacco Research Institute, 445-820 Dangsu-Ri, Banwol-Myun, Hwasong-Kun, Kyonggi, Korea

\author{
Sung-Sik Lee \\ Jungpyong Experiment Station, Korean Ginseng and Tobacco Research Institute, 367-900, Chojung-Ri, \\ Jungpyong- Up, Kwaesan-Kun, Choongbuk, Korea
}

Ginseng (Panax ginseng C.A. Meyer) "has been a mysterious cure-all medicine in Asia for several thousand years" (Hong, 1978). Early reports from Koguryo (which includes present-day Korea) state that wild-growing ginseng was taken to China in 435-546 (Hong, 1978). Inevitably, collecting the native plant depleted the natural stand (this was noted in 1567-1608) and led to cultivation under artificial shade. Today the plant is protected worldwide by CITES, the Convention on International Trade in Endangered Species (Singer, 1982). Most production of ginseng is under artificial shade modified by local requirements and expertise (for China, see Proctor et al., 1988). A small amount of ginseng is still collected from native stands or cultivated under forest canopies. The purpose of this report is to provide information about the Korean ginseng industry as part of our continuing attempt to make information about world ginseng cultivation readily available (Proctor and Bailey, 1987; Proctor et al., 1988).

Growing ginseng in the Republic of Korea. Ginseng is native to Korea and, although somewhat rare, can still be found in mountainous areas, particularly in northern parts. The area within which it is cultivated is from $36^{\circ}$ to $38^{\circ} \mathrm{N}$ (Fig. 1). Inside this area are two regions of ginseng production-one in the south centered around Daejeon and one in the north, the major area, bounded by the demilitarized zone and the two coasts. Local soil types and microclimate within these two regions dictate which type of ginseng,

Received for publication 2 Mar. 1989. J.T.A.P. is indebted to the Government of the Republic of Korea, through its Office of Monopoly and the Korean Ginseng and Tobacco Research Institute, for financial support of his study tour of Korea. Necessary additional financial support was made possible through Operating Grant no. A6697 of the Natural Sciences and Engineering Research Council of Canada held by J.T.A.P. Ido Schechter and Debbie Wilson are thanked for technicalassistance during preparation of this manuscript. We are indebted to numerous Korean research and extension personnel and growers who gave so freely of their time, experience, and hospitality, The cost of publishing this paper was defrayed in part by the payment of page charges. Under postal regulations, this paper therefore must be hereby marked advertisement solely to indicate this fact. red or white, is cultivated. At harvest, ginseng root is naturally yellowish white and is dried in sunlight or placed in forced-air driers. The resultant product is called white ginseng. At harvest in Korea, an alternative procedure is to select 6-year-old yellowish white roots and steam them to a reddishbrown before drying them in the sun. This product is known as red ginseng. Major production of red ginseng is in the north.

The Office of Monopoly of the Korean Government regulates all aspects of ginseng collection, cultivation, manufacturing, sales, and export. This control ensures development of an export strategy for an entire industry and stable returns to growers. Red ginseng is classified as a monopoly item. Government approval is required for cultivating red ginseng and it must be grown 1 year in a seedling nursery and 5 years in transplanted raised beds covered with shade (Figs. 2 and 3). The amount that is authorized to be seeded is determined by demand and supply and is aimed at guaranteeing stable income for growers and increasing the national revenue. White ginseng is grown for 4 to 6 years.

Planting area, particularly for red ginseng, increased dramatically between 1982 and 1984 , but has decreased somewhat since then (Table 1). This change has not been reflected greatly in the amount harvested, e.g., 917 ha planted in 1984 and only 461 ha $(50 \%)$ harvested in 1988. Disease incidence has been high during this period and probably accounts for much of the area not meeting the high grades required for red ginseng and, therefore, being harvested and handled as

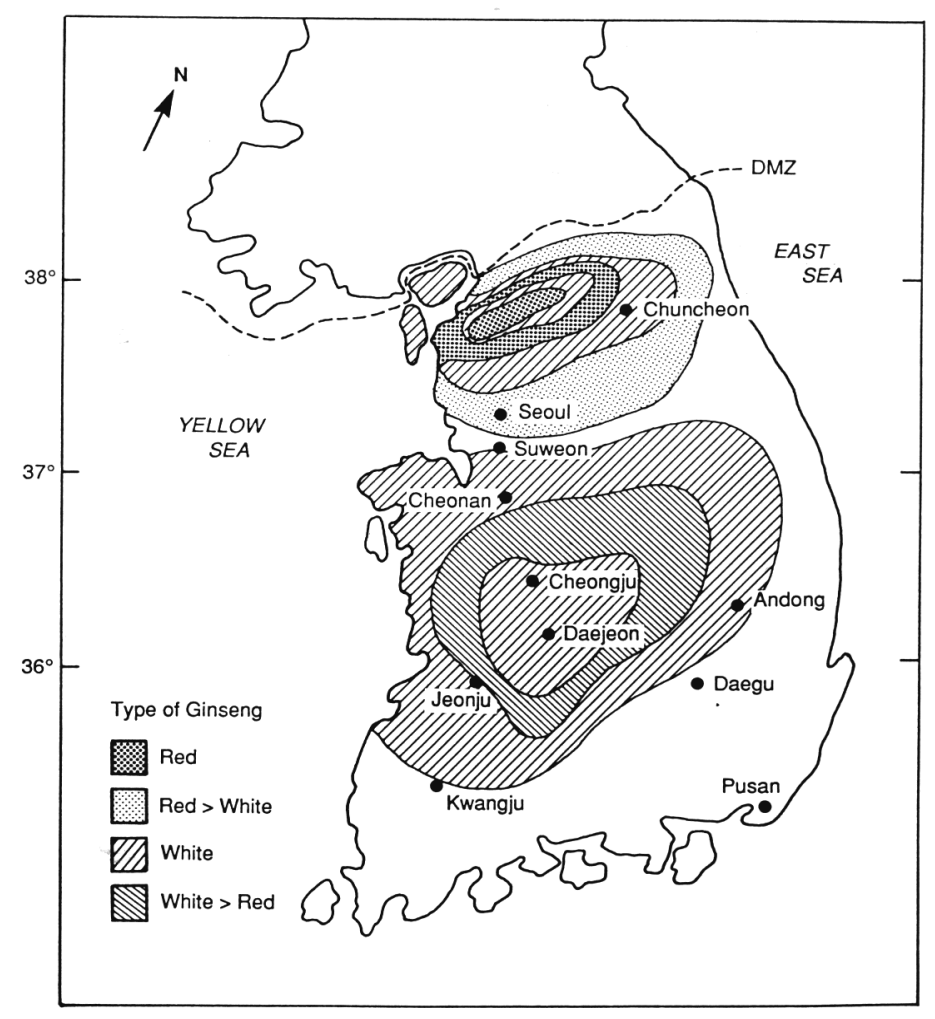

Fig. 1. Map of South Korea showing the two major ginseng-producing regions, types of ginseng grown within these regions, and the major cities. (DMZ = demilitarized zone; border with North Korea). 


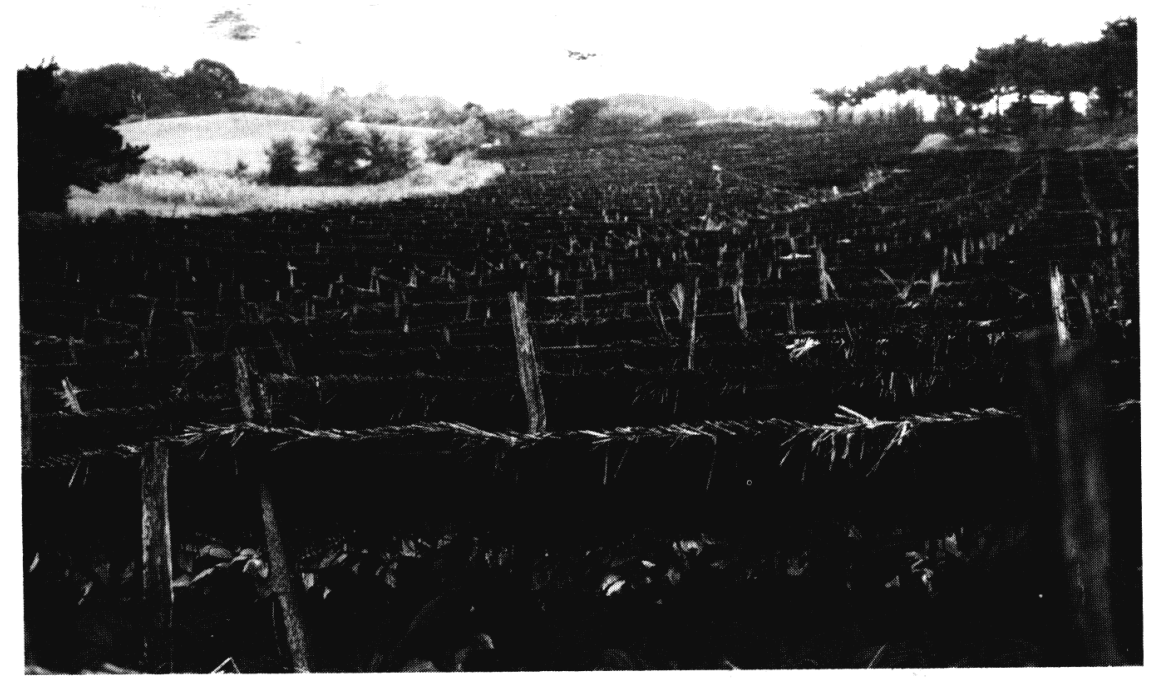

Fig. 2. A typical ginseng garden in Korea occupying $\approx 2$ ha.

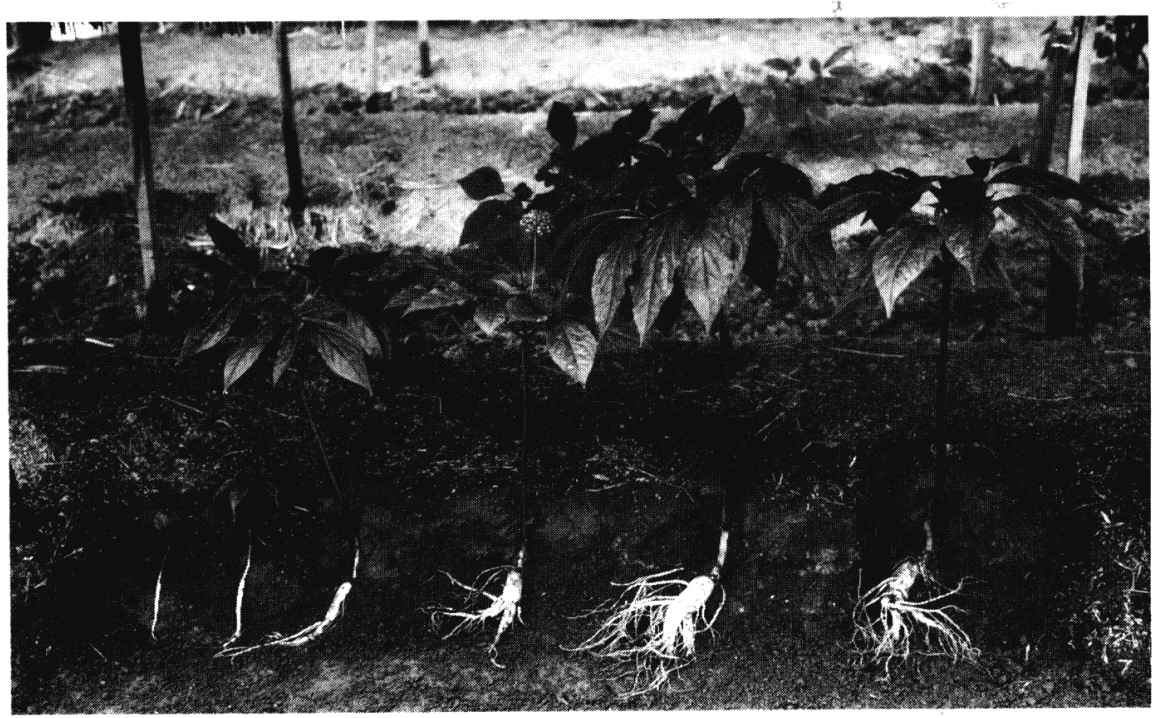

Fig. 3. Korean ginseng plants, from 1 (left) to 6 years old (right). Seed production is obvious by year 4 . Root fresh weights during years 1 through 6 are $\approx 0.5,8,40,70,100$, and $125 \mathrm{~g}$, respectively.

Table 1. Area of Korean red and white ginseng planted and harvested and total yield of root from 1982 to 1988.

\begin{tabular}{|c|c|c|c|c|c|c|c|}
\hline & \multicolumn{7}{|c|}{ Year } \\
\hline & 1982 & 1983 & 1984 & 1985 & 1986 & 1987 & 1988 \\
\hline \multicolumn{8}{|c|}{ Area planted (ha) } \\
\hline Red & 240 & 700 & 920 & 830 & 890 & 800 & 700 \\
\hline White & 1900 & 2100 & 2,690 & 2,840 & 2,850 & 2800 & 2,800 \\
\hline Total & 2140 & 2800 & 3,610 & 3,670 & 3,740 & 3600 & 3,500 \\
\hline \multicolumn{8}{|c|}{ Area harvested (ha) } \\
\hline Red & 240 & 280 & 420 & 460 & 440 & 403 & 460 \\
\hline White & 2180 & 2040 & 2,910 & 2,990 & 3,180 & 2720 & 3,190 \\
\hline Total & 2420 & 2320 & 3,330 & 3,450 & 3,620 & 3120 & 3,650 \\
\hline \multicolumn{8}{|c|}{ Total yield $(t)$} \\
\hline Freshy & 7330 & 7020 & 10,100 & 10,470 & 10,950 & 9730 & 11,060 \\
\hline Dry $^{x}$ & 2200 & 2100 & 3,030 & 3,140 & 3,280 & 2920 & 3,320 \\
\hline
\end{tabular}

${ }^{2}$ Data supplied by the Korea Monopoly Corp.

'Root yield is based on an average yield of $1.5 \mathrm{~kg}$ fresh weight per $3.3 \mathrm{~m}^{2}$ and that 0.66 of the total area was cropped.

${ }^{x}$ Yield dry weight was calculated using a dry matter content of $30 \%$. white ginseng. Standards for producing red ginseng are very high and include application for producing only in specified areas and government approval to harvest. There are no such restrictions on cultivating areas for white ginseng, and digging has to be reported, not approved.

Total production has been fairly constant at $\approx 3000 \mathrm{t}$ since 1984 (Table 1). Using 1988 figures, this gives $908 \mathrm{~kg} \cdot \mathrm{ha}^{-1}$. As noted previously (Proctor et al., 1988), this is a low yield, but does not take into account root size or other characteristics of quality.

Marketing. At harvest, the fresh roots must be dried to maintain quality and avoid breakdown in storage. Quality grading of white roots is done mainly by external characteristics, such as the thickness and length of the main and lateral roots, surface color, and degree of blemishing by diseases and insects. The five grades for red ginseng are known as "Heaven" (1st), "Earth" (2nd), "Good" (3rd), "Cut" (4th), and "Tails" (5th). A wide range of processed products are made from both red (4th and 5th grades) and white ginseng-for specific examples, see Table 2.

The export value of Korean ginseng has increased steadily since 1965 (Table 3). In $1987,41 \%$ of total exports was whole red ginseng roots followed by $30 \%$ manufactured products of white ginseng, $23 \%$ whole white ginseng roots, and $7 \%$ manufactured products of red ginseng.

Manufactured white ginseng products. There are many types of products made from Korean ginseng, including extracts, tea, drinks, gum, and candy. The extracts are originally made with a solvent and then concentrated. They are easy to dissolve in water and have the characteristic ginseng flavor with a slightly bitter taste. Ginseng tea is a major product and is usually in a granulated or powdered form with sugar (Song, 1978). The value of some of these products in 1985 indicates that domestic worth was about twice that of export (Table 3).

Production practices. Present-day practices for cultivating ginseng in Korea have been developed over centuries. However, there remain problems, challenges, and opportunities from which Westerners can learn.

Seed propagation. The principal means of propagating ginseng is by seed (Proctor and Bailey, 1987). Seed germination is not easily achieved because of dormancy-controlling mechanisms that are poorly understood. Normally, American ginseng germinates 18 to 22 months after seed harvest (Polczinski, 1982). In Korea, the Oriental ginseng is stratified in sand outdoors in a wooden box or drained cement cylinder (Fig. 4) from seed harvested in mid-July until early November (Park and Lee, 1981: Korea Monopoly Corp., 1987). The freshly harvested seed must not be treated with fungicides because such applications decrease subsequent germination. The seed and sand are mixed 1:3 (v/v) and placed in the container (Fig. 4). Water is added to the container until the excess is observed draining out, twice daily from late July to mid-September, once per day until 
Table 2. Value (unit, US\$1000) of various Korean manufactured white ginseng products exported or sold domestically in 1985 . $^{2}$

\begin{tabular}{lrrr}
\hline \hline \multirow{2}{*}{$\begin{array}{l}\text { Manufactured } \\
\text { product }\end{array}$} & & Sales (US\$1000) & Total \\
\cline { 2 - 4 } Extract & Export & Domestic & 22,540 \\
Powder & 16,800 & 5,740 & 1,712 \\
Capsule/tablet & 1,360 & 352 & 863 \\
Extract powder & 534 & 329 & 1,540 \\
Tea & 1,540 &.-- & 22,930 \\
Tang-sam (boiled water extract) & 5,930 & 17,000 & 1,724 \\
Drink & 234 & 1,490 & 28,500 \\
Nectar & 900 & 27,600 & 1,790 \\
Leaf powder & 22 & 1,760 & 14 \\
Ginseng chicken soup & 14 &.-- & 79 \\
Gum and candy & 79 &.-- & 6,713 \\
Tonic & 83 & 6,630 & 457 \\
Others & 44 & 413 & 443 \\
Total & 260 & 183 & 92,200 \\
\hline
\end{tabular}

${ }^{2}$ Data supplied by the Korea Monopoly Corp.

Table 3. Export value (unit, US\$1000) of Korean red and white ginseng and their manufactured products in selected years from 1965 to $1987 .^{2}$

\begin{tabular}{rrrrrr}
\hline \hline & $\begin{array}{c}\text { Red } \\
\text { Yinseng }\end{array}$ & $\begin{array}{c}\text { Manufactured } \\
\text { products of } \\
\text { red ginseng }\end{array}$ & $\begin{array}{c}\text { White } \\
\text { ginseng }\end{array}$ & $\begin{array}{c}\text { Manufactured } \\
\text { products of } \\
\text { white ginseng }\end{array}$ & Total \\
\hline & & Export value & $($ US\$1000) & & \\
1965 & 1,280 & 15 & 840 & 9 & 2,140 \\
1970 & 4,100 & 56 & 5,060 & 20,300 & 9,930 \\
1975 & 11,500 & 4,000 & 5,970 & 28,400 & 65,900 \\
1980 & 29,100 & 6,000 & 2,440 & 25,200 & 57,100 \\
1981 & 20,700 & 5,490 & 5,790 & 24,500 & 69,400 \\
1982 & 33,300 & 6,000 & 5,650 & 25,500 & 75,300 \\
1983 & 33,500 & 7,210 & 9,010 & 25,900 & 86,800 \\
1984 & 33,800 & 8,000 & 19,100 & 27,800 & 73,000 \\
1985 & 20,000 & 8,830 & 16,400 & 34,200 & 115,000 \\
1987 & 46,600 & 8,000 & 25,900 & &
\end{tabular}

Data supplied by the Korea Monopoly Corp.

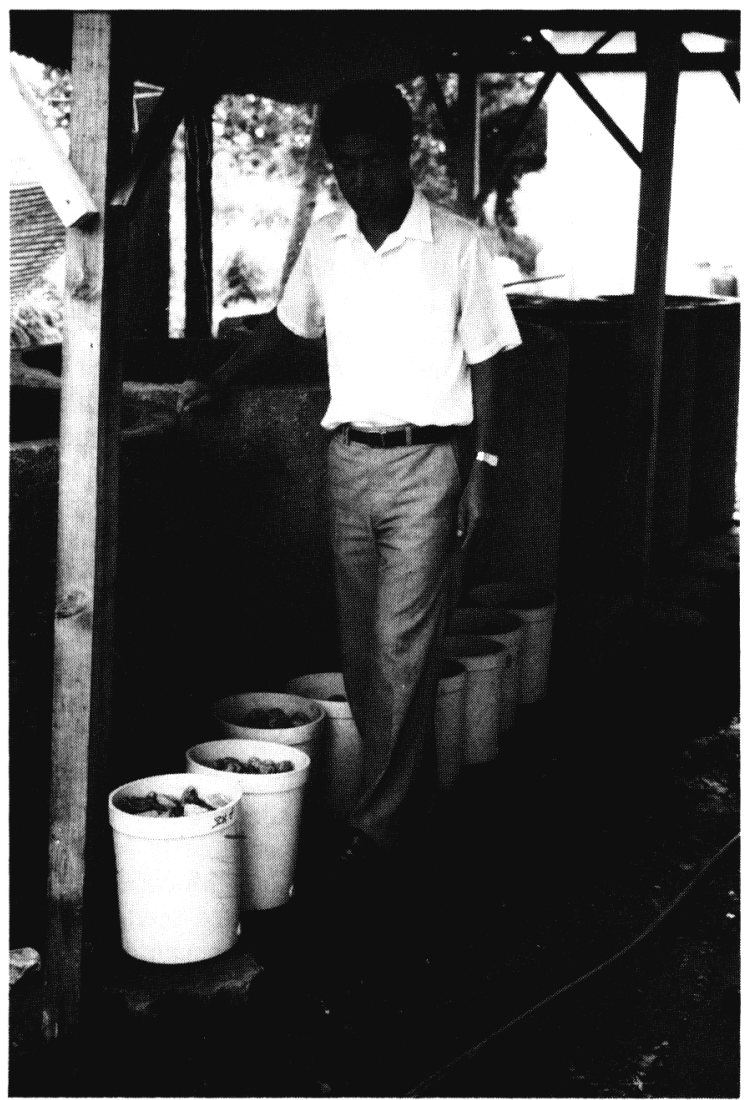

mid-October, and then once every 2 or 3 days until early November. The estimated required water content of the sand is $10 \%$ to $15 \%$. Excess water decreases subsequent seed germination. The above treatment causes seed coat cracking and embryo growth.

The treated seeds then are planted in the nursery bed in early November and germinate the following spring, $\approx 8$ months after seed harvest. This Korean technology has not been adapted for American ginseng, in spite of the reduction in germination time from 18 to 8 months after seed harvest. Jo et al. (1988) recently suggested that stratification at $20 \mathrm{C}$ of American ginseng immediately after seed harvest for embryo activation, followed by transfer to $15 \mathrm{C}$ for embryo growth, might allow early germination.

Shade. Koreans have recognized that it is necessary to change their shade structures and garden design for ginseng production to increase light penetration and consequent yields (Lee et al., 1980; Proctor and Bailey, 1987). The impermeable thatch shade of straw or reeds (Fig. 2) does not allow enough light to reach the rows in the back of the bed, and access to the beds for spraying and weeding is difficult. Research has been initiated to develop a different shade material (Fig. 5). Since these experiments take a minimum of 6 years to complete, recommendations for the industry are not yet forthcoming. A major unresolved problem is that the shade should permit enough light to reach the plants, but should not allow the heavy rains of the summer monsoons to hit the plants directly.

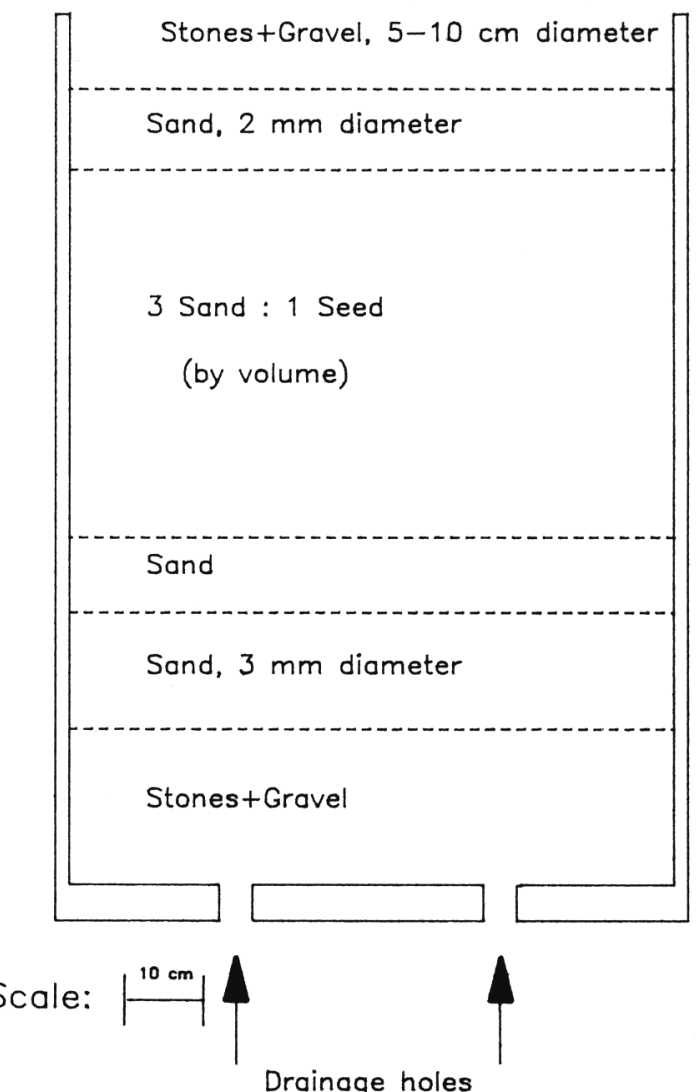

Fig. 4. After-ripening treatment of "green" Korean seed immediately following fruit harvest and seed extraction. (left) Large concrete containers filled with seed, sand, gravel, and stones to which water is added frequently. All are protected by a roof. (right) Diagram of the container and its contents. 


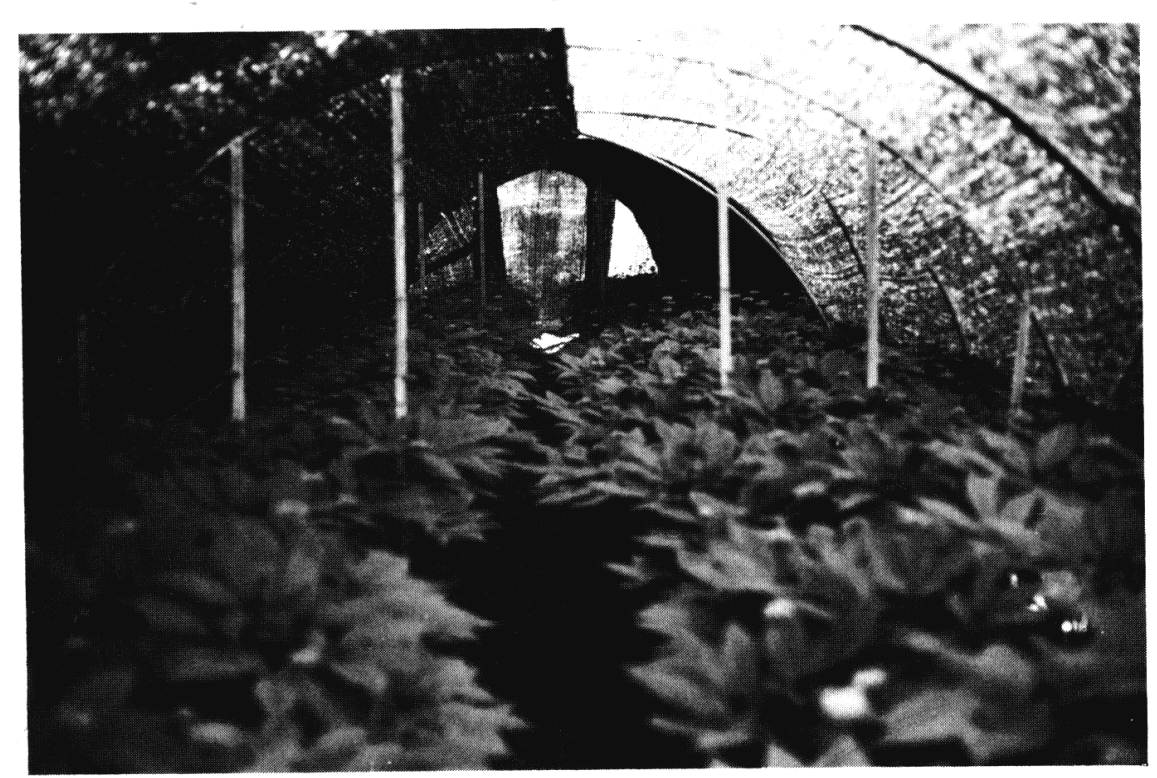

Fig. 5. Experimental black plastic shade arranged like a quonset greenhouse. Shades with light transmission from $5 \%$ in the right rear to $20 \%$ in the front right arc being evaluated.

Pest control. Generally, the pest problems of ginseng, particularly diseases, are similar wherever ginseng is grown (Proctor and Bai- ley, 1987: Proctor et al., 1988). Within each growing area, specific climatic factors may accentuate pest problems. For instance, in
China (Proctor et al., 1988), summer monsoons may restrict' pesticide application and allow spread of diseases. Korea also experiences summer monsoons (Proctor and Lee, 1981), and similar disease problems exist.

A list of major pest problems in Korea and chemicals applied for their control is given in Table 4. Because of the size and importance of the ginseng industry to Korea, a large arsenal of control chemicals has been developed. In contrast, only three chemicals (anilazine, iprodione, and mancozeb) are registered in Canada, and a few registered chemicals have limited use in the United States (Heize, 1984). In spite of the availability of chemicals in Korea, disease control remains the central problem in production, as it does in the rest of the world.

Pesticide application is usually by a spray gun attached by a hose to a central spray mixing and pumping station, similar to that described and illustrated for spraying of fruit trees (Proctor and Lee, 1981). The parallel in North American ginseng production, until $\approx 20$ years ago, was the tractor-drawn tank and pump to which was attached a hose and spray gun. The tractor was parked next to the ginseng gardens and spraying carried out by pulling the hoses through the gardens.

Table 4. Some common pest problems in Korean ginseng production and chemicals used for control.

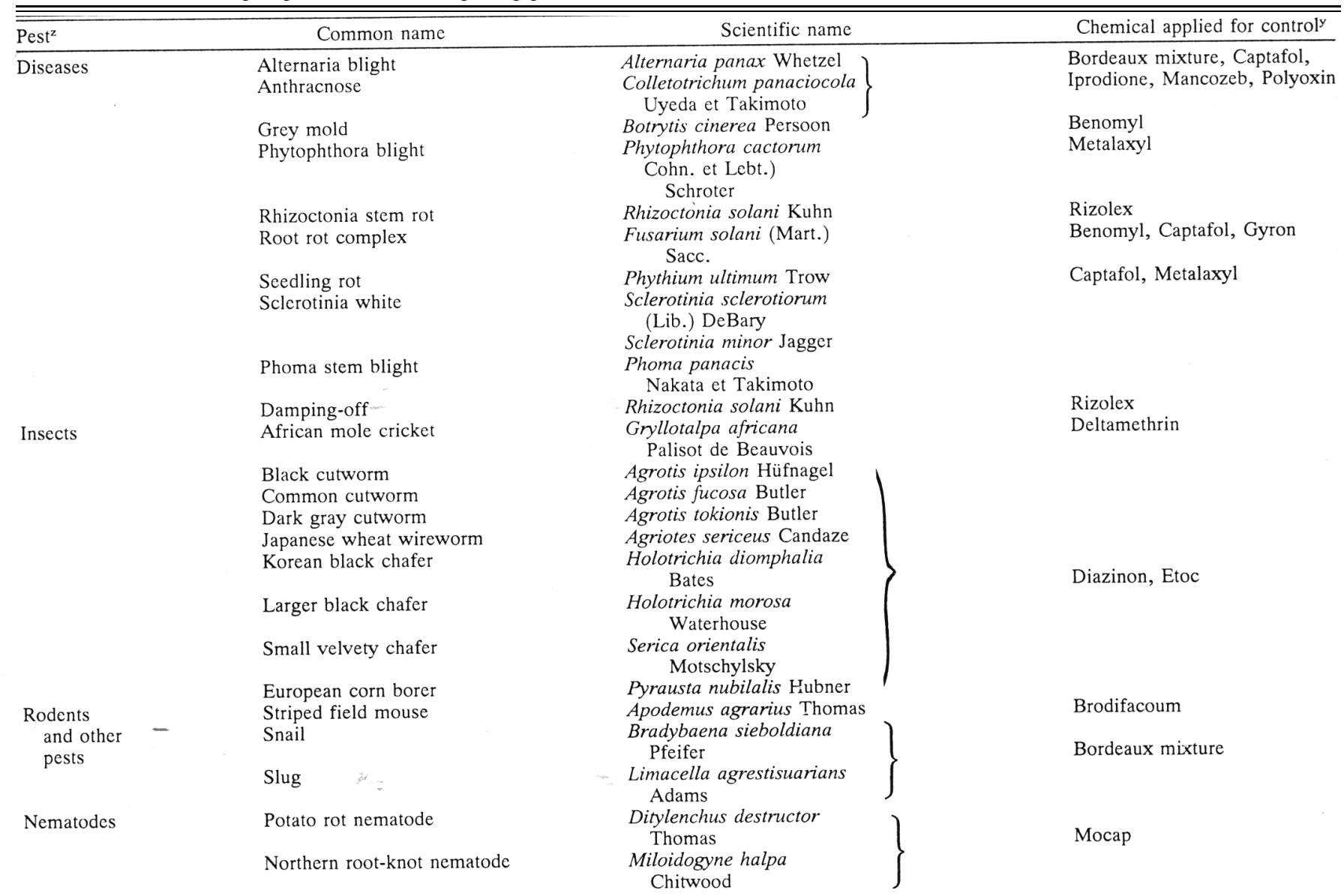

'Pests listed are taken from Korean Monopoly Corp. et al., (1984).

"Although specific chemicals are mentioned, they should be regarded only as examples and in no way are to be considered as recommendations. The primary source for this listing was the "Standard methods of ginseng cultivation", Korea Monopoly Corp. (1987). 
Changes in garden structure and sprayer development in North America have seen the advent of the cart-mounted sprayer and wide boom that is driven through the gardens (Proctor et al., 1988). Such developments have not occurred yet in Korea because of the necessary radical changes needed in garden design and shade structure.

The future. Korea is the largest or second largest producer of ginseng in the world (Proctor et al., 1988). Expanding production, strong field and laboratory research programs, product development, and a highly organized and aggressive world-wide marketing system should ensure continuation of this leadership. Markets should expand because of a gradual shift towards a holistic approach in Western medicine and use of ethnic herbal medicines rather than Western synthetics.

\section{Literature Cited}

Heize, L. 1984. Problems with pesticide registra- tion and ginseng export, p. 53-60. In: J.T.A. Proctor (ed.). Proc. Sixth North American Ginseng Conference, Univ. of Guelph, Guelph, Ont., Canada.

Hong, S.K. 1978. Ginseng cultivation, p. 245272. In: H.W. Bae (ed.). Korean ginseng. Korean Ginseng Res. Inst., Seoul.

Jo, J., F.A. Blazich, and T.R. Konsler. 1988. Postharvest seed maturation of American ginseng: stratification temperatures and delay of stratification. HortScicnce 23:995-997.

Korea Monopoly Corp. 1987. Standard methods of ginseng cultivation. 3rd ed. Shintanjin, Korea.

Korean Monopoly Corp., Korea Ginseng and Tobacco Research Inst., and Ginseng Growers Assn. of Korea. 1984. Ginseng: Diseases, insects and color pictures. Korea Monopoly Corp., Shintangin, Korea.

Lee, J.C., S.K. Cheon, Y.T. Kim, and J.S. Jo, 1980. Studies on the effect of shading materials on the temperature, light intensity, photosynthesis, and the root growth of Korean ginseng (Panax ginseng C.A. Meyer). J. Korean Soc. Crop Sci. 2.5:91-98.
Park, H. and C.H. Lee. 1981. Cultural practices of Panax ginseng in Korea, p. 32-34. In: N.A. Lapp (ed.). Proc. Third Natl. Ginseng Conf., Asheville, N.C.

Polczinski, L.C. 1982. Ginseng (Panax quinquefolius L.) culture in Marathon County, Wisconsin: Historical growth, distribution and soils inventory. MS Thesis. Univ. of Wisconsin, Stevens Point.

Proctor, J.T.A. and W.G. Bailey. 1987. Ginseng: Industry, botany and culture. Hort. Rev. 9:187236.

Proctor, J.T.A. and J.C. Lee. 1981. The apple industry in Korea. HortScience 16:609-614.

Proctor, J.T.A., T.S. Wang, and W.G. Bailey. 1988. East meets west: Cultivation of American ginseng in China. HortScience 23:968-973.

Singer, S.R. 1982. Export of American ginseng from the United States, p. 77-86. In: C.R. Roberts and J. English (eds.). Proc. Fifth Natl. Ginseng Conf., Lexington, Ky.

Song, Y.D. 1978. Manufacture of ginseng products, p. 221-242. In: H.W. Bae (ed.). Korean ginseng. Korean Ginseng Res. Inst., Seoul. 